\title{
Treatment Selection for Ruptured Aneurysm and Outcomes: Clipping or Coil Embolization
}

\author{
Hiroshi TEnJIn, ${ }^{1}$ Michiko TAKADOU, ${ }^{1}$ Takahiro OGAWA, ${ }^{1}$ \\ Ayako MANDAI, ${ }^{1}$ Daisuke UMEBAYASHI, ${ }^{1}$ Yasuhiko OSAKA, ${ }^{1}$ \\ Yoshikazu NAKAHARA, ${ }^{1}$ and Satoshi KUBO ${ }^{1}$ \\ ${ }^{1}$ Department of Neurosurgery, Kyoto Second Red Cross Hospital, Kyoto
}

\begin{abstract}
The International Subarachnoid Aneurysm Trial has shown that coil embolization achieves a better outcome for aneurysms treatable by either clipping or coil embolization. However, many ruptured aneurysms are hardly treatable by either clipping or coil embolization. Selection of either clipping or coil embolization will affect the treatment outcome for ruptured aneurysms. The relationship between patient selection and treatment outcome in a so-called "regional center hospital" in Japan must be clarified. This study included 113 patients with ruptured intracranial saccular aneurysms measuring less than $10 \mathrm{~mm}$. Selection criteria for coil embolization were principally paraclinoid or posterior circulation aneurysm, Hunt and Hess grade IV or over, and patient age 75 years or older. Other aneurysms were principally treated by clipping. Aneurysms with a dome/neck ratio of less than 1.5, distorted aneurysms, Hunt and Hess grades I-III, patient age 74 years or younger, and middle cerebral artery aneurysm were actively treated by clipping. A few exceptional indications were considered in detail. Low invasiveness coil embolization is better than clipping to obtain good neurological outcome for patients with perforators difficult to dissect, aneurysms difficult to dissect due to previous open surgery, and aneurysms requiring bilateral open surgery, despite the slightly higher rebleeding rate in coil embolization. Overall outcomes were modified Rankin Scale (mRS) 0-2 in 82 of 113 patients (73\%) and mRS 3-6 in 31 (27\%). Appropriate selection of clipping or coil embolization can achieve acceptable treatment outcomes for ruptured aneurysm.
\end{abstract}

Key words: ruptured aneurysm, clipping, coil embolization, indication, outcome

\section{Introduction}

The International Subarachnoid Aneurysm Trial (ISAT) has shown that coil embolization achieves better outcomes for aneurysms treatable by either clipping or coil embolization, but the rebleeding rate is higher after coil embolization. ${ }^{5)}$ However, randomization was performed for only $22.4 \%$ of the patients. In clinical practice, all ruptured aneurysms must be treated by either clipping or coil embolization, but many cases are difficult to treat by one or the other of these methods. Preoperative grade and patient age are also important factors affecting outcome. Selection of either clipping or coil embolization affects the treatment outcome for ruptured aneurysms. The relationship between patient selection and treatment outcome in a so-called "regional center hospital" in Japan should be clarified, de-

Received March 29, 2010; Accepted September 17, 2010 fined as a hospital to which most patients with ruptured aneurysm in the region are transported.

The present study analyzes cases of ruptured aneurysms treated by clipping or coil embolization using selection criteria based on the location and morphology of aneurysm, preoperative grade, and patient age in our hospital, and discusses some additional other factors influencing selection.

\section{Patients and Methods}

This study included 113 patients with ruptured intracranial saccular aneurysms measuring less than $10 \mathrm{~mm}$ treated between April 2006 and January 2010. Aneurysms larger than $11 \mathrm{~mm}$ were excluded because of the unsatisfactory outcome of coil embolization for such aneurysms. Patients with Hunt and Hess $(\mathrm{H} \& \mathrm{H})$ grade $\mathrm{V}$ before surgery, but not on admission, were also excluded.

All patients were admitted and underwent surgery within 48 hours after onset. Surgery was performed 
under general anesthesia. For coil embolization, adjunctive techniques were sometimes used, such as the double catheter technique and neck plasty. Cisternal drainage was placed during clipping and spinal drainage was placed immediately after coil embolization and maintained for around 2 weeks following treatment. Administration of fasudil hydrochloride was started on the day after clipping and 2 days after coil embolization, and continued for 2 weeks. If symptomatic spasm developed, sodium ozagrel was also administered. If hydrocephalus developed, ventriculoperitoneal shunting was performed. The outcome was evaluated around 2 months after onset using the modified Rankin Scale (mRS). The range of mRS 0-2 was defined as a good outcome.

Patient selection was based on the severity of subarachnoid hemorrhage, age, and morphology and location of the aneurysm. Selection criteria for coil embolization were principally paraclinoid or posterior circulation aneurysm, H\&H grade IV or over, and patient age 75 years or older. Other aneurysms were principally treated by clipping. Aneurysms with a dome/neck ratio of less than 1.5, distorted aneurysms, H\&H grades I-III, patient age 74 years or younger, and middle cerebral artery aneurysm were treated actively by clipping. However, the final treatment selection was additionally based on detailed considerations of the relationship between the aneurysm and surrounding arteries, especially the perforators, brain swelling, and hematoma thickness. In principle, 61 patients were indicated only for clipping, 34 patients only for coil embolization, and 18 patients were indicated for either treatment. Treatment selection was exceptional in 13 patients.

The distribution of aneurysms and selection of treatment are shown in Fig. 1, with 77 aneurysms $(68 \%)$ treated by clipping and $36(32 \%)$ by coil embolization. Patient age distribution is shown in Fig. 2 . The mean age of patients treated by clipping was $59.1 \pm 12.4$ years, and that of patients treated by coil embolization was significantly higher at $71.5 \pm 11.6$ years ( $\mathrm{p}<0.05$ by Wilcoxon rank sum test).

Statistical analyses examined the relationships between patient age, treatment, and outcome (chisquare test), relationships between neurological grade before surgery, treatment, and outcome (chisquare test), outcomes for paraclinoid and posterior circulation aneurysms, specific causes for poor outcome in patients with good preoperative neurological grade, relationship between rebleeding rate and treatment (chi-square test), specific causes for rebleeding, and outcomes of patients with exceptional treatment selection.

\section{Results}

The relationships between age, treatment, and outcome are shown in Fig. 3. The outcomes of treatment by clipping or coil embolization showed no significant differences between patients aged 69 years or younger and patients aged 70 years or older. However, combination of both groups demonstrated that patients aged 69 years or younger had significantly better outcomes than patients aged 70 years or older ( $p<0.05$ by chi-square test).

The relationships between preoperative neurolog-

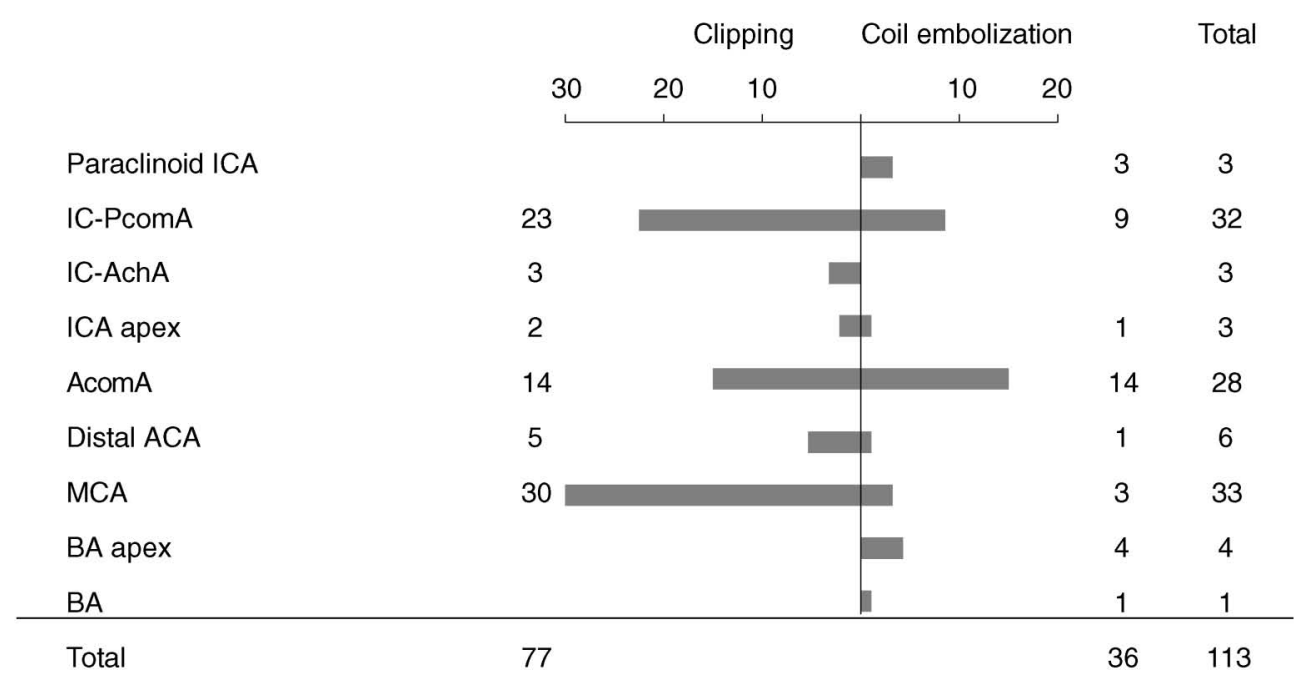

Fig. 1 Distribution of aneurysms. ACA: anterior cerebral artery, AcomA: anterior communicating artery, BA: basilar artery, ICA: internal carotid artery, IC-PcomA: internal carotid-posterior communicating artery bifurcation, IC-AchA: internal carotid-anterior choroidal artery bifurcation, MCA: middle cerebral artery. 


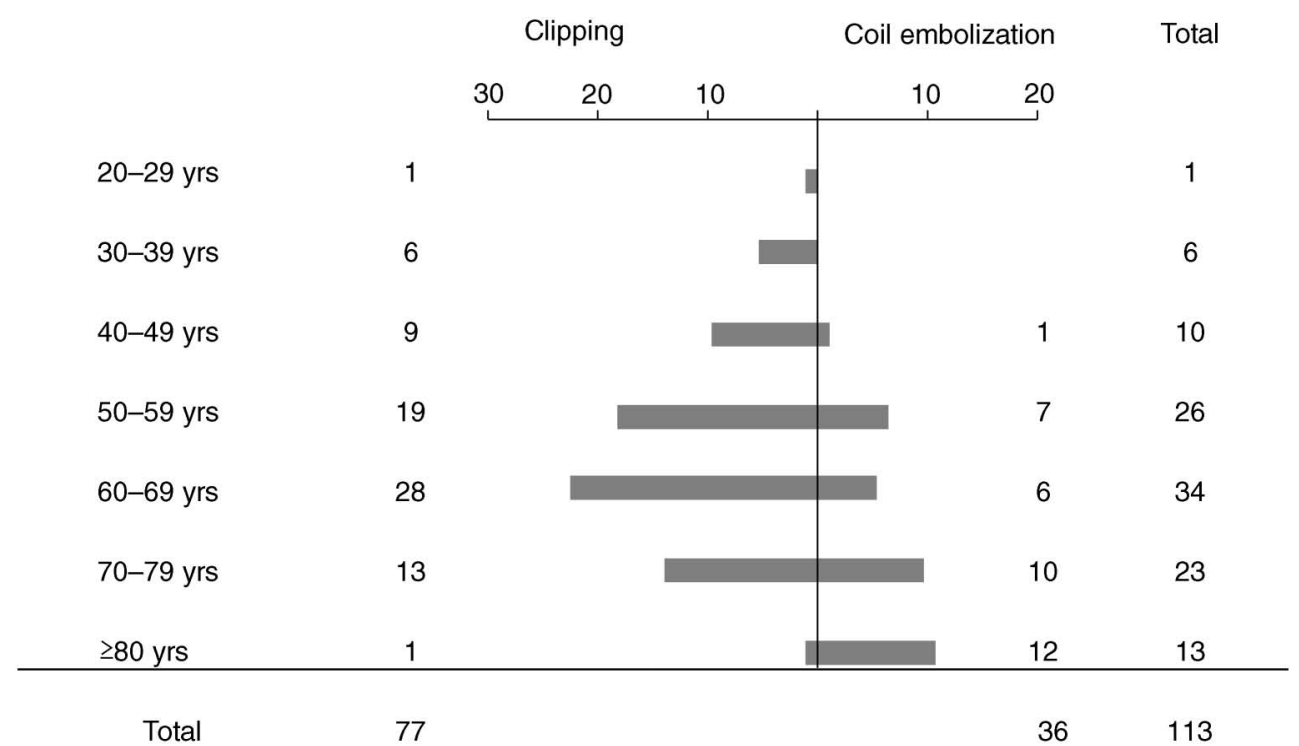

Fig. 2 Patient age distribution.

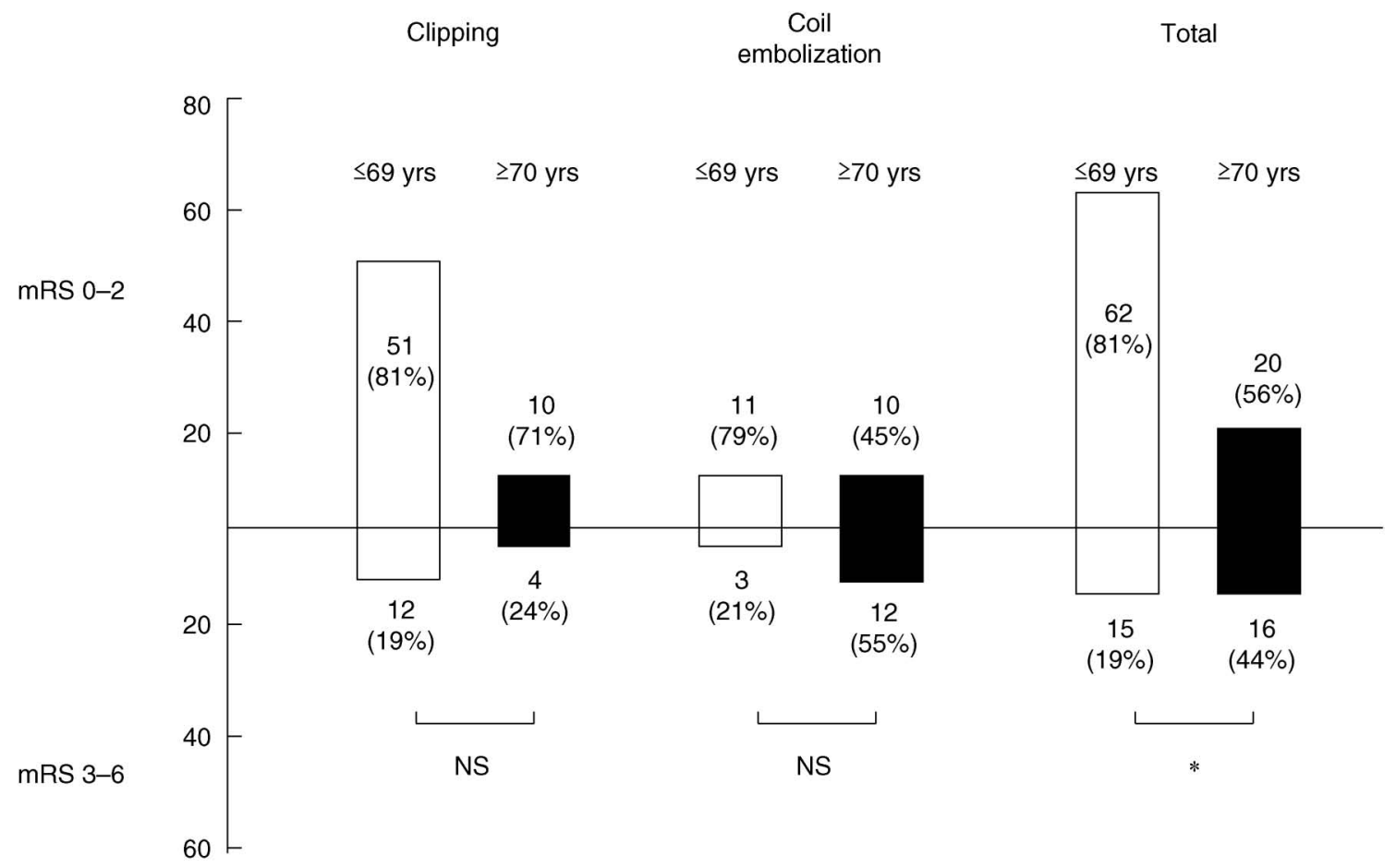

Fig. 3 Relationships between age, treatment, and outcome. ${ }^{*} p<0.05$ by chi-square test. mRS: modified Rankin Scale, NS: not significant. Open columns: age 69 years or younger, closed columns: age 70 years or older.

ical grade, treatment, and outcome are shown in Fig. 4 and Table 1. Patients treated by clipping or coil embolization with $\mathrm{H} \& \mathrm{H}$ grades I-III were both significantly more likely to achieve good outcomes compared with patients with $\mathrm{H} \& \mathrm{H}$ grade IV ( $\mathrm{p}<$ 0.05 by chi-square test). Combination of all patients treated by clipping and coil embolization showed similar findings ( $\mathrm{p}<0.05$ by chi-square test). Over- all outcomes were mRS $0-2$ in 82 of 113 patients $(73 \%)$ and mRS $3-6$ in $31(27 \%)$.

Three internal carotid artery paraclinoid portion aneurysms and 5 posterior circulation aneurysms were treated by coil embolization. Two patients with poor outcomes had preoperative $\mathrm{H} \& \mathrm{H}$ grade IV, indicating that outcomes of aneurysms in this location reflected the preoperative grade. 


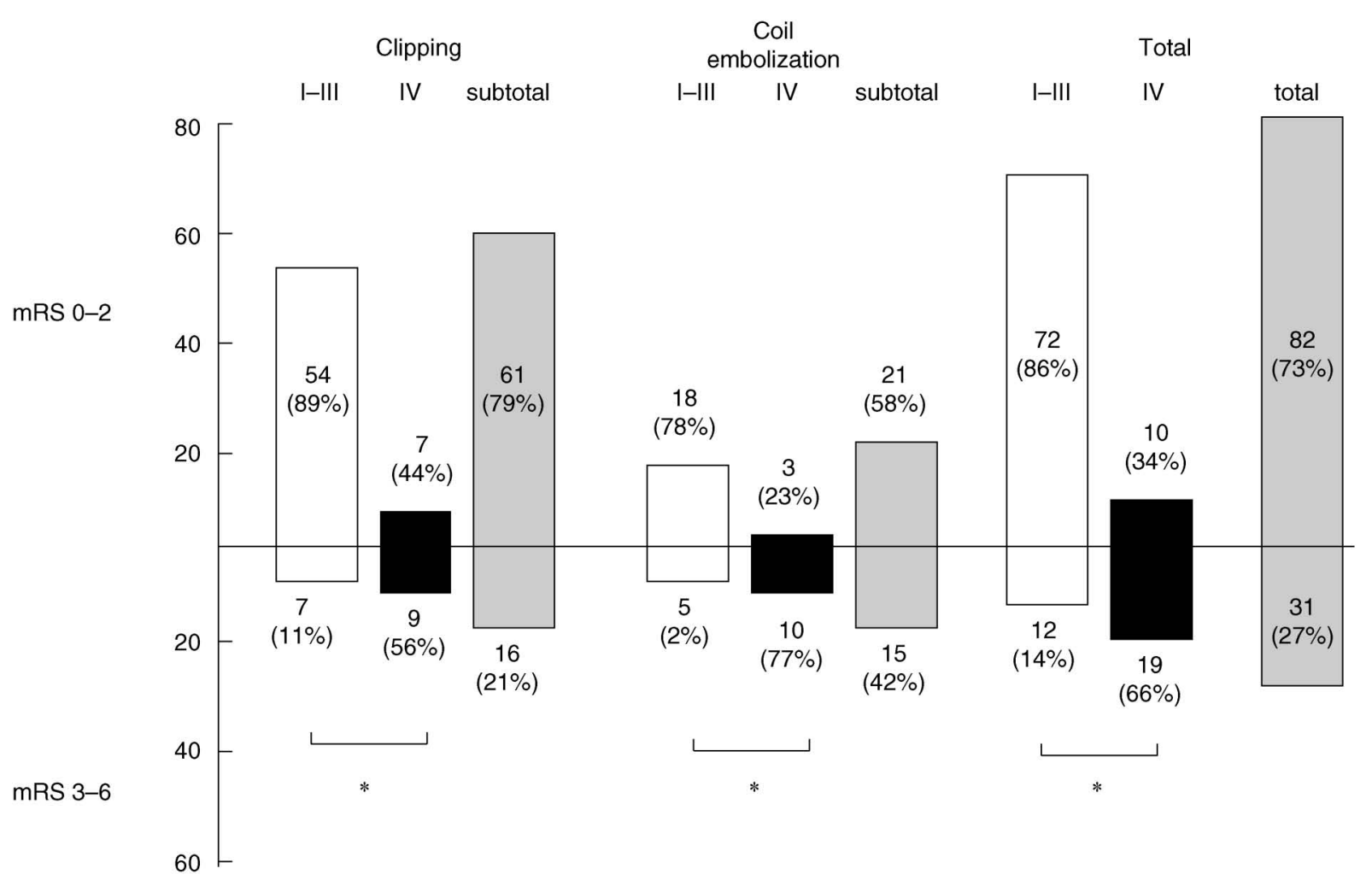

Fig. 4 Relationships between preoperative neurological grade, treatment, and outcome. ${ }^{*}$ p $<0.05$ by chi-square test. mRS: modified Rankin Scale. Open columns: Hunt and Hess grades I-III, closed columns: Hunt and Hess grade IV, shaded columns: Hunt and Hess grades I-IV.

Table 1 Relationships between preoperative neurological grade, treatment, and outcome

\begin{tabular}{lrrrrrrr}
\hline \multirow{2}{*}{$\begin{array}{c}\text { Preoperative H\&H } \\
\text { grade }\end{array}$} & \multicolumn{7}{c}{ Outcome (mRS) } \\
\cline { 2 - 7 } Clipping & 0 & 1 & 2 & 3 & 4 & 5 & 6 \\
$\quad$ I & 6 & 5 & 0 & 0 & 0 & 0 & 0 \\
II & 9 & 1 & 4 & 1 & 1 & 0 & 1 \\
III & 16 & 1 & 12 & 2 & 2 & 0 & 0 \\
IV & 0 & 0 & 7 & 1 & 6 & 1 & 1 \\
Coil embolization & & & & & & & \\
I & 3 & 1 & 1 & 0 & 0 & 0 & 0 \\
II & 1 & 1 & 2 & 0 & 0 & 0 & 1 \\
III & 3 & 2 & 4 & 1 & 2 & 0 & 1 \\
IV & 0 & 0 & 3 & 2 & 3 & 2 & 3 \\
\hline
\end{tabular}

H\&H: Hunt and Hess, mRS: modified Rankin Scale.

Patients with good preoperative neurological grade but poor outcome are shown in Table 2. After clipping, seven patients showed poor outcome: one developed rebleeding, one underwent second surgery, one elderly underwent bilateral surgery, one suffered perforator injury, two had aphasia and hemiparesis on admission, and one was elderly. After coil embolization, five patients showed poor out- comes: two developed rebleeding, two had aphasia and hemiparesis on admission, and one was elderly. The most suitable treatment was given for any complications.

Patients with rebleeding and the causes are shown in Table 3. Rebleeding rates were 2 of 77 patients $(2.6 \%)$ after clipping and 3 of $36(8.3 \%)$ after coil embolization, without significant difference by chisquare test. Causes of rebleeding were aneurysm remnant hidden behind the aneurysm or parent artery in two cases treated by clipping, and inadequate coil embolization in three cases, due to protrusion of one loop of the coil into the parent artery, inability to embolize the neck of the infantile type posterior communicating artery aneurysm, and broad neck of the middle cerebral artery aneurysm.

Patients treated by exceptional selections and outcomes are shown in Table 4. Clipping was chosen as an exceptional selection in seven patients. Three of the seven patients showed mRS 0-2, and four showed mRS 3-6. Five of the seven patients had internal carotid-posterior communicating artery bifurcation aneurysms. Although the shape of the posterior communicating artery was the usual reason for exceptional selection of clipping, good outcomes were achieved in around half of these 
Table 2 Patients with good preoperative neurological grade but poor outcome and the causes

\begin{tabular}{|c|c|c|c|c|}
\hline $\begin{array}{l}\text { Age } \\
\text { (yrs), } \\
\text { Sex }\end{array}$ & $\begin{array}{l}\text { Preoperative } \\
\text { H\&H grade }\end{array}$ & $\begin{array}{l}\text { Location of } \\
\text { aneurysm }\end{array}$ & Treatment & Cause of poor outcome; Treatment of complications \\
\hline $68, \mathrm{~F}$ & II & AcomA & clipping & $\begin{array}{l}\text { rebleeding; } \\
\text { coil embolization }\end{array}$ \\
\hline $73, \mathrm{~F}$ & II & $\begin{array}{l}\text { rt } \mathrm{MCA} \\
\text { bifurcation }\end{array}$ & clipping & $\begin{array}{l}\text { severe vasospasm was induced because MCA aneurysm was difficult to } \\
\text { dissect due to previous surgery for ICA aneurysm; } \\
\text { treatment for vasospasm }\end{array}$ \\
\hline 59, M & III & lt ICA apex & clipping & aphasia and rt hemiparesis due to perforator injury \\
\hline $86, \mathrm{~F}$ & III & rt IC-PcomA & clipping & $\begin{array}{l}\text { elderly, shock due to blood discharge from bowels (exceptional selection); } \\
\text { blood infusion }\end{array}$ \\
\hline $61, \mathrm{~F}$ & III & lt IC-PcomA & clipping & aphasia and rt hemiparesis on admission \\
\hline $57, \mathrm{~F}$ & III & $\begin{array}{l}\text { rt } \mathrm{MCA} \\
\text { bifurcation }\end{array}$ & clipping & lt hemiparesis on admission \\
\hline $88, \mathrm{~F}$ & III & $\begin{array}{l}\text { lt } \mathrm{MCA} \\
\text { bifurcation }\end{array}$ & coil & $\begin{array}{l}\text { lt MCA aneurysm with hematoma, aphasia and rt hemiparesis on } \\
\text { admission }\end{array}$ \\
\hline $79, \mathrm{~F}$ & III & lt IC-PcomA & coil & $\begin{array}{l}\text { rebleeding; } \\
\text { treatment for severe brain swelling }\end{array}$ \\
\hline $82, \mathrm{~F}$ & III & rt IC-PcomA & coil & elderly, blind, and gait disturbance before onset \\
\hline
\end{tabular}

AcomA: anterior communicating artery, F: female, H\&H: Hunt and Hess, ICA: internal carotid artery, IC-PcomA: internal carotid-posterior communicating artery bifurcation, lt: left, M: male, MCA: middle cerebral artery, rt: right.

Table 3 Patients with rebleeding and the causes

\begin{tabular}{|c|c|c|c|}
\hline $\begin{array}{l}\text { Age (yrs), } \\
\text { Sex }\end{array}$ & $\begin{array}{l}\text { Preoperative } \\
\text { H\&H grade }\end{array}$ & Treatment & Cause of rebleeding \\
\hline $68, \mathrm{~F}$ & II & clipping & $\begin{array}{l}\text { AcomA aneurysm; } \\
\text { complete clipping had been expected during surgery, but an aneurysm remnant } \\
\text { was hidden behind the AcomA }\end{array}$ \\
\hline $69, \mathrm{~F}$ & IV & clipping & $\begin{array}{l}\text { IC-PcomA aneurysm with severe consciousness disturbance (III-100); } \\
\text { complete clipping had been expected during surgery, but an aneurysm remnant } \\
\text { was hidden behind the aneurysm }\end{array}$ \\
\hline $79, \mathrm{~F}$ & III & coil & $\begin{array}{l}\text { IC-PcomA aneurysm; } \\
\text { the neck of the infantile type PcomA aneurysm could not be embolized completely }\end{array}$ \\
\hline $61, F$ & IV & coil & $\begin{array}{l}\text { lt MCA aneurysm with severe consciousness disturbance (III-200); } \\
\text { coil embolization was chosen to prevent delayed vasospasm, but was incomplete } \\
\text { because of broad neck }\end{array}$ \\
\hline
\end{tabular}

AcomA: anterior communicating artery, F: female, IC-PcomA: internal carotid-posterior communicating artery bifurcation, lt: left, M: male, MCA: middle cerebral artery.

patients. Coil embolization was chosen as an exceptional selection in six patients, for five anterior communicating artery and one internal carotid artery apex aneurysms. The reason for selecting coil embolization was preservation of the perforator. All patients demonstrated outcomes of mRS 0-2.

\section{Discussion}

The factors influencing poor outcome are preoperative neurological grade, patient age, location, and aneurysm size. ${ }^{2,4,10,12)}$ In this study, aneurysms larger than $11 \mathrm{~mm}$ were excluded, because the result of coil embolization is not satisfactory due to coil compaction. ${ }^{9,13)}$ During this period, 7 aneurysms larger than 
Table 4 Patients treated by exceptional selections and outcomes

\begin{tabular}{ccllc}
\hline $\begin{array}{c}\text { Age (yrs), } \\
\text { Sex }\end{array}$ & $\begin{array}{c}\text { Preoperative } \\
\text { H\&H grade }\end{array}$ & $\begin{array}{c}\text { Location of } \\
\text { aneurysm }\end{array}$ & Treatment & $\begin{array}{c}\text { Outcome } \\
\text { (mRS) }\end{array}$ \\
\hline $69, \mathrm{M}$ & IV & AcomA & clipping & 4 \\
$66, \mathrm{~F}$ & IV & IC-PcomA & clipping & 2 \\
$60 . \mathrm{F}$ & IV & IC-PcomA & clipping & 4 \\
$78, \mathrm{~F}$ & II & IC-PcomA & clipping & 0 \\
$78, \mathrm{~F}$ & I & IC-PcomA & clipping & 0 \\
$50, \mathrm{~F}$ & IV & distal ACA & clipping & 5 \\
$69, \mathrm{~F}$ & IV & IC-PcomA & clipping & 5 \\
$67, \mathrm{~F}$ & III & AcomA & coil & 2 \\
$74, \mathrm{~F}$ & III & ICA apex & coil & 0 \\
$70, \mathrm{~F}$ & II & AcomA & coil & 0 \\
$67, \mathrm{~F}$ & I & AcomA & coil & 0 \\
$58, \mathrm{M}$ & III & AcomA & coil & 0 \\
$58, \mathrm{M}$ & I & AcomA & coil & 1 \\
\hline
\end{tabular}

ACA: anterior cerebral artery, AcomA: anterior communicating artery, F: female, $\mathrm{H} \& \mathrm{H}$ : Hunt and Hess, ICA: internal carotid artery, IC-PcomA: internal carotidposterior communicating artery bifurcation, $\mathrm{M}$ : male, mRS: modified Rankin Scale.

$11 \mathrm{~mm}$ were treated. Although clipping was indicated as the first selection, 4 aneurysms were actually treated by coil embolization because of the poor grade, and one of those four was later changed to clipping due to coil compaction. ${ }^{9}$ In this study, the mean diameter of aneurysms treated by clipping was $4.6 \pm 1.5 \mathrm{~mm}$, and that of those treated by coil embolization was $5.6 \pm 2.5 \mathrm{~mm}$. Aneurysms treated by coil embolization tended to be larger than those treated by clipping, although there was no significant difference.

Previous studies have reported good or fair outcomes after clipping in $47 \%$ of patients aged between 70 and 79 years, ${ }^{4)}$ and excellent or good outcomes after coil embolization in $43 \%$ of patients older than 70 years. ${ }^{1)}$ In this study, 62 of 77 patients (81\%) aged 69 years or younger showed mRS 0-2 whereas 15 of 77 (19\%) showed mRS 3-6, and 20 of 36 patients $(56 \%)$ aged 70 years or older showed mRS 0-2 whereas 16 of 36 (44\%) showed mRS 3-6. The difference in outcome between elderly and young patients was significant. This finding is comparable to those of previous reports.

In a previous study, Sundt et al. reported $93 \%$ of patients with preoperative $\mathrm{H} \& \mathrm{H}$ grades $\mathrm{I}-\mathrm{II}, 84 \%$ with $\mathrm{H} \& \mathrm{H}$ grade III, $51 \%$ with $\mathrm{H} \& \mathrm{H}$ grade IV, and $23 \%$ with $\mathrm{H} \& \mathrm{H}$ grade $\mathrm{V}$ showed excellent or good outcomes. ${ }^{12)}$ Also, Yasargil et al. reported 95\% of patients with $\mathrm{H} \& \mathrm{H}$ grades I-III and $28 \%$ with $\mathrm{H} \& \mathrm{H}$ grades IV-V had excellent or good outcomes. ${ }^{14)}$ Investigation of patients with poor preoperative grade indicated that $38 \%$ of patients with $\mathrm{H} \& \mathrm{H}$ grades IV-V showed good outcome, ${ }^{8)}$ and $64 \%$ of patients with H\&H grade IV showed good outcome with early ventriculostomy. ${ }^{3)}$ Every study of coil embolization has included some clipping cases, but Ross et al. reported $46 \%$ of patients with $\mathrm{H} \& \mathrm{H}$ grades IV-V showed good results after coil embolization. ${ }^{11)}$ In this study, 72 of 84 patients (86\%) with $\mathrm{H} \& \mathrm{H}$ grades I-III and 10 of 29 (34\%) with H\&H grade IV showed outcomes of mRS $0-2$. The difference between the outcomes of patients in good and poor preoperative grades was significant. This finding is comparable to those of previous reports. Coil embolization was selected for elderly patients and those with poor preoperative grade, so this study already had selection bias. The overall outcome of coil embolization cannot be simply compared with that of clipping. ${ }^{7)}$

Yasargil et al. reported only $9 \%$ of patients with basilar artery aneurysm showed poor outcomes or died. ${ }^{14)}$ In our study, all patients with paraclinoid or basilar artery aneurysm in H\&H grades I-III showed mRS $0-2$ following coil embolization. The outcomes of aneurysms in this location were also attributed to the preoperative grade. This outcome is comparable to previously reported results.

The ISAT study showed rebleeding rates of $1 \%$ following clipping and $2.7 \%$ following coil embolization, ${ }^{5)}$ and the difference was not significant. In our study, the rebleeding rate was $2.6 \%$ following clipping and $8.3 \%$ following coil embolization, and this difference was not significant. This study probably included many aneurysms that were difficult to treat by either clipping or coil embolization. If coil embolization does not seem adequate, we recommend that the patient be managed by inducing low blood pressure and remaining in a quiet environment for 1 or 2 days during completion of intraaneurysmal thrombosis. ${ }^{6)}$

This study showed that patient age and preoperative grade are important factors affecting outcome after both clipping and coil embolization. Location is also concerned with outcome, but the outcomes of patients with paraclinoid or basilar artery aneurysm treated by coil embolization were attributed to preoperative grade. Therefore, the difficulty associated with location is less important. To develop more selection criteria, poor outcomes in patients with good preoperative grade and patients treated by exceptional selection can be analyzed. Of the patients with good preoperative grade but poor outcome, one patient developed rebleeding after clipping, two patients were treated by highly invasive clipping (one underwent second surgery and one was elderly and underwent bilateral surgery), one patient sustained perforator injury during clipping, and two patients had rebleeding after coil embolization. Other patients with good preoperative grade 
but poor outcome had hemiparesis or aphasia on admission. Six patients mainly with anterior communicating artery aneurysms were exceptionally selected for coil embolization to preserve perforators, and demonstrated outcomes of mRS 0-2. The findings in patients with good preoperative grade but poor outcome and in patients with exceptional selection suggest that low invasiveness coil embolization is better than clipping to obtain good neurological outcome for patients with perforators difficult to dissect, aneurysms difficult to dissect due to previous open surgery, and aneurysms requiring bilateral open surgery, despite the slightly increased rebleeding rate in coil embolization. Actual selection of treatment will also involve informed consent considering patient background, lifestyle, and desires before rupture of the aneurysm.

In the present series of 113 ruptured intracranial saccular aneurysms under $10 \mathrm{~mm}$ in diameter, selection criteria for coil embolization were principally paraclinoid or posterior circulation aneurysm, $\mathrm{H} \& \mathrm{H}$ grade IV or over, and patient age 75 years or older. Other aneurysms were principally treated by clipping. Aneurysms with a dome/neck ratio of less than 1.5, distorted aneurysms, H\&H grades I-III, patient age 74 years or younger, and middle cerebral artery aneurysm were actively treated by clipping. A few exceptional indications were also considered in detail, including perforators and surgical invasiveness. Low invasiveness coil embolization is better than clipping to obtain good neurological outcome beyond the principal criteria for patients with perforators difficult to dissect, aneurysms difficult to dissect due to previous open surgery, and aneurysms requiring bilateral open surgery, despite the slightly higher rebleeding rate in coil embolization. Overall outcomes were mRS $0-2$ in $73 \%$ and mRS $3-6$ in $27 \%$ of patients. Appropriate selection of clipping or coil embolization can achieve acceptable treatment outcomes of ruptured aneurysm in a so-called "regional center hospital."

\section{References}

1) Chung RY, Carter BS, Norbash A, Budzik R, Putnam C, Oglivy CS: Management outcomes for ruptured and unruptured aneurysms in the elderly. Neurosurgery 47: 827-833, 2000

2) Elliott JP, Le Roux PD: Subarachnoid hemorrhage and cerebral aneurysms in the elderly. Neurosurg Clin N Am 9: 587-594, 1998

3) Gumprecht H, Winkler R, Gerstner W, Lumenta CB: Therapeutic management of grade IV aneurysm patients. Surg Neurol 47: 54-59, 1997

4) Inagawa $T$, Yamamoto $M$, Kamiya $K$, Ogasawara $H$ :
Management of elderly patients with aneurysmal subarachnoid hemorrhage. J Neurosurg 69: 332-339, 1988

5) International Subarachnoid Aneurysm Trial (ISAT) Collaborate Group: International Subarachnoid Aneurysm Trial (ISAT) of neurosurgical clipping versus endovascular coiling in 2143 patients with ruptured intracranial aneurysms: a randomized trial. Lancet 360: 1267-1274, 2002

6) Johnston SC, Dowd CF, Higashida RT, Lawton MT, Duckwiler GR, Gress DR; CARAT Investigators: Predictors of rehemorrhage after treatment of ruptured intracranial aneurysms: the Cerebral Aneurysm Rerupture After Treatment (CARAT) study. Stroke 39: 120-125, 2008

7) Kato Y, Sano H, Dong PT, Panji N, Itezawa Y, Hayashi J, Kanno T: The effect of clipping and coiling in acute severe subarachnoid hemorrhage after international subarachnoid aneurysmal trial (ISAT) results. Minim Invasive Neurosurg 48: 224-227, 2005

8) Le Roux PD, Elliott JP, Newell DW, Grady MS, Winn HR: Predicting outcome in poor-grade patients with subarachnoid hemorrhage: a retrospective review of 159 aggressively managed cases. J Neurosurg 85: 39-49, 1996

9) Osaka Y, Tenjin H, Nakahara Y, Yamamoto S, Umebayashi D, Mandai A, Ogawa T, Takadou M: [Acute partial endovascular coiling of large ruptured aneurysms in cases of critical]. Surgery for Cerebral Stroke 37: 443-446, 2009 (Japanese)

10) Peerless SJ, Drake CG: Management of aneurysms of the posterior circulation, in Youmans JR (ed): Neurological Surgery. A Comprehensive Reference Guide to the Diagnosis and Management of Neurosurgical Problems, 3rd ed. Philadelphia, Saunders, 1990, pp 1764-1806

11) Ross J, O’Sullivan MG, Grant IS, Sellar R, Whlttle IR: Impact of early endovascular aneurysmal occlusion on outcome of patients in poor grade subarachnoid haemorrhage: a prospective, consecutive study. J Clin Neurosci 9: 548-552, 2002

12) Sundt TM Jr: Results of surgical management, in Sundt TM Jr (ed): Surgical Techniques for Saccular and Giant Intracranial Aneurysms. Baltimore, Williams \& Wilkins, 1990, pp 19-23

13) Vinuela F, Duckwiler G, Mawad M: Guglielmi detachable coil embolization of acute intracranial aneurysm: perioperative anatomical and clinical outcome in 403 patients. J Neurosurg 86: 475-482, 1997

14) Yasargil MG: Clinical considerations, in Yasargil MG (ed): Microneurosurgery II. Clinical Considerations, Surgery of the Intracranial Aneurysms and Results. New York, Thieme-Stratton, 1984, pp 1-32

Address reprint requests to: Hiroshi Tenjin, MD, Department of Neurosurgery, Kyoto Second Red Cross Hospital, Kamanza-Marutamachi, Kamigyo-ku, Kyoto 602-8026, Japan.

e-mail: htenjin@nn.iij4u.or.jp 